\title{
Whole-Body Lipolysis and Triglyceride-Fatty Acid Cycling in Cachectic Patients with Esophageal Cancer
}

\author{
Samuel Klein* and Robert R. Wolfe ${ }^{\star}$ \\ Departments of ${ }^{*}$ Internal Medicine, ${ }^{*}$ Preventive Medicine and Community Health, ${ }^{\ddagger}$ Surgery, and ${ }^{\ddagger}$ Anesthesiology, \\ The University of Texas Medical Branch and the Shriners Burns Institute, Galveston, Texas 77550
}

\begin{abstract}
Whole-body lipolytic rates and the rate of triglyceride-fatty acid cycling (reesterification of fatty acids released during lipolysis) were measured with stable isotopic tracers in the basal state and during $\beta$-adrenergic blockade with propranolol infusion in five cachectic patients with squamous cell carcinoma of the esophagus, five cachectic cancer-free, nutritionallymatched control patients, and 10 healthy volunteers. Resting energy expenditure and plasma catecholamines were normal in all three groups. The basal rate of glycerol appearance in blood in the patients with cancer $\left(2.96 \pm 0.45 \mu \mathrm{mol} \cdot \mathrm{kg}^{-1} \cdot \mathrm{min}^{-1}\right)$ was similar to that in the nutritionally matched controls $(3.07 \pm 0.28$ $\left.\mu \mathrm{mol} \cdot \mathrm{kg}^{-1} \cdot \mathrm{min}^{-1}\right)$, but $48 \%$ greater than in the normal-weight volunteers $\left(2.00 \pm 0.16 \mu \mathrm{mol} \cdot \mathrm{kg}^{-1} \cdot \mathrm{min}^{-1}\right)(P=0.028)$. The antilipolytic effect of propranolol and the rate of triglyceridefatty acid cycling in the patients with cancer were also similar in the cachectic control group and $\sim 50 \%$ greater than in the normal-weight volunteers, but the differences were not statistically significant because of the variability in the data.

We conclude that the increase in lipolysis and triglyceride-fatty acid cycling in "unstressed" cachectic patients with esophageal cancer is due to alterations in their nutritional status rather than the presence of tumor itself. Increased $\beta$ adrenergic activity may be an important contributor to the stimulation of lipolysis. (J. Clin. Invest. 1990. 86:1403-1408.) Key words: stable isotopes $\bullet$ lipolysis • cancer cachexia
\end{abstract}

\section{Introduction}

During the course of their illness, patients with cancer often lose weight, depleting body protein and fat $(1,2)$. Understanding the mechanisms involved in loss of body fat may be clinically important because weight loss itself is a bad prognostic sign $(3,4)$ and the amount of remaining fat in starved individuals has been shown to correlate closely with the duration of survival (5). Although the precise mechanisms responsible for the decline in body fat are not completely understood, an imbalance between intake and expenditure of energy must exist so that fatty acids released from stored triglycerides are oxidized for fuel. The consumption of endogenous energy

Address correspondence and reprint requests to Samuel Klein, M.D., Division of Gastroenterology, G-64, The University of Texas Medical Branch, Galveston, TX 77550.

Received for publication 7 February 1990 and in revised form 25 April 1990.

J. Clin. Invest.

(C) The American Society for Clinical Investigation, Inc.

0021-9738/90/11/1403/06\$\$2.00

Volume 86, November 1990, 1403-1408 stores may be related to decreased caloric intake or increased energy expenditure or both. Studies performed in animals suggest that loss of fat is not caused by decreased food intake alone. Lipid depletion occurs even before the onset of anorexia in mice (6) and is more severe in tumor-bearing animals than in pair-fed controls (7). The observation that lipolytic rates measured in epididymal fat pads of tumor-bearing mice (8) and rats (9) are two- to threefold greater than in normal animals suggests that increased rates of lipolysis contribute to the loss of body fat provided that fat oxidation is also increased.

In humans the effect of cancer on lipid metabolism is unclear. Whole-body lipolytic rates in patients with cancer have been reported to be both normal $(10,11)$ and increased (12-14), and the basal rate of fat oxidation has been reported to be both normal $(12,15)$ and increased (14). A rapid loss of fat mass could occur if both lipolysis and fatty acid oxidation are increased. An increase in lipolysis without an equal and parallel increase in fatty acid oxidation would cause an increase in triglyceride-fatty acid (TG-FA) ${ }^{1}$ cycling, which occurs when fatty acids released during lipolysis are subsequently reesterified back to triglyceride. Although TG-FA cycling does not result in any net flux of reactants, it does require energy and may increase metabolic rate. Several studies have found the resting metabolic rate to be increased in patients with cancer (16-18). In other clinical conditions in which both energy expenditure and lipolytic rates are increased, such as burn injury, an increase in TG-FA cycling accounted for a significant proportion of the increase in energy expenditure (19).

$\beta$-Adrenergic activity is an important regulator of lipolysis, energy expenditure, and TG-FA cycling in healthy humans $(20,21)$. In burn injury, when plasma catecholamine concentrations are high, $\beta$-adrenergic activity has been demonstrated to be a potent stimulator of both lipolysis and TG-FA cycling (16). Elevated plasma catecholamines in patients with cancer have been reported, suggesting adrenergic stimulation as a possible mechanism for increased lipolysis and TG-FA cycling (22).

The present study was performed to evaluate energy expenditure, whole-body lipolytic rates, TG-FA cycling, and the importance of $\beta$-adrenergic stimulation on lipolysis in cachectic patients with squamous cell carcinoma of the esophagus. Cachectic patients who did not have cancer and normalweight volunteers were also studied to distinguish the effects of cancer itself from those of malnutrition. Stable isotopic tracers were used to determine lipid kinetics by measuring the rates of appearance ( $\mathrm{Ra}$ ) of glycerol and palmitic acid in blood plasma.

1. Abbreviations used in this paper: GCMS, gas chromatography mass spectrometry; m/e, mass-to-charge ratio; $R_{\mathrm{a}}$, rate of appearance; REE, resting energy expenditure; TG-FA, triglyceride-fatty acid. 
Lipolytic rates in the basal state and during propranolol infusion were evaluated to quantify the contribution of $\beta$-adrenergic activity.

\section{Methods}

Subjects. This study was approved by the Institutional Review Board and Clinical Research Center of The University of Texas Medical Branch at Galveston. Five cachectic patients with biopsy-proved squamous cell carcinoma of the esophagus, five cancer-free cachectic patients, and 10 healthy volunteers of normal weight were studied. The characteristics of the study subjects are shown in Table I. Cachectic patients were defined as those who had lost $10 \%$ or more of body weight during the 6 mo before the study. The percentage of body weight lost in each patient with cancer was matched with that in a cachectic cancer-free control patient. The amount of body weight loss was determined by patient history and interview with at least one close family member living in the same household. All patients with cancer were carefully selected so that they. had the same type of tumor, no other illness or inflammatory condition, no metastases, and no previous anticancer therapy to avoid confounding influences on the experimental results. The tumors were circumferential and caused dysphagia in all patients. Tumor lengths ranged from 4 to $10 \mathrm{~cm}$ (mean \pm SE, $7 \pm 1 \mathrm{~cm}$ ). All subjects received a comprehensive medical examination including history and physical examination, routine blood tests, thyroid function studies, and electrocardiogram. Subjects with anemia or hypertension or with endocrinologic, cardiac, pulmonary, renal, hepatobiliary, or inflammatory diseases were excluded. No patient was taking any medications at the time of the study. The normal volunteers were of normal weight for height as determined by the 1983 Metropolitan Life Insurance Tables.

Study protocol. Each subject was admitted to the Clinical Research Center and given a standard meal (12 kcal/kg Ensure [Ross Laboratories, Columbus, $\mathrm{OH}$ ) during the afternoon and evening before the metabolic studies. After subjects were fasted overnight (12 h), Teflon catheters were inserted into the antecubital vein of one arm for infu-

Table 1. Characteristics of the Study Subjects

\begin{tabular}{|c|c|c|c|}
\hline & $\begin{array}{l}\text { Cachectic patients } \\
\text { with esophageal } \\
\text { cancer* } \\
n=5\end{array}$ & $\begin{array}{l}\text { Cachectic patients } \\
\text { without cancer } \\
n=5\end{array}$ & $\begin{array}{c}\text { Normal-weight } \\
\text { volunteers } \\
n=10\end{array}$ \\
\hline \multicolumn{4}{|l|}{ Age $(y r)$} \\
\hline Mean \pm SE & $58 \pm 2$ & $58 \pm 7$ & $31 \pm 2$ \\
\hline Range & $50-64$ & $30-70$ & $24-40$ \\
\hline Sex & $4 \mathrm{M}, 1 \mathrm{~F}$ & $4 \mathrm{M}, 1 \mathrm{~F}$ & $10 \mathrm{M}$ \\
\hline \multicolumn{4}{|l|}{ Height $(\mathrm{cm})$} \\
\hline Mean \pm SE & $174 \pm 4$ & $173 \pm 4$ & $176 \pm 2$ \\
\hline Range & $159-180$ & $160-182$ & $168-186$ \\
\hline \multicolumn{4}{|l|}{ Weight $(\mathrm{kg})$} \\
\hline Mean \pm SE & $58 \pm 4$ & $52 \pm 6$ & $72 \pm 2$ \\
\hline Range & $47-66$ & $39-72$ & $64-83$ \\
\hline \multicolumn{4}{|c|}{ \% Ideal body weight } \\
\hline Mean \pm SE & $83 \pm 4$ & $75 \pm 5$ & $100 \pm 1$ \\
\hline Range & $71-91$ & $64-90$ & $97-103$ \\
\hline \multicolumn{4}{|c|}{$\begin{array}{c}\% \text { Weight loss in } \\
\text { last } 6 \text { mo }\end{array}$} \\
\hline Mean \pm SE & $18 \pm 3$ & $19 \pm 3$ & 0 \\
\hline Range & $10-28$ & $10-30$ & 0 \\
\hline
\end{tabular}

* Squamous cell carcinoma of esophagus.

‡ Malabsorption, esophageal motility disorder, esophageal stricture, poor dentition, and depression. M, male; F, female. sion of isotopes and propranolol and into the contralateral dorsal hand vein, which was heated, for arterialized venous sampling (23). The subjects remained in bed for $60 \mathrm{~min}$ after catheter placement to ensure resting conditions before proceeding with the study. In five normalweight volunteers, only baseline lipolytic rates were measured. In the other five normal-weight volunteers and in all the cachectic subjects, baseline lipolytic rates, TG-FA cycling, and the antilipolytic response to propranolol were determined. Oxygen consumption, carbon dioxide production, and resting energy expenditure (REE) were determined with a Horizon metabolic measurement cart and face mask system (Sensormedics Corp., Anaheim, CA). Measurements were taken over a 15-min period while the subjects lay comfortably in a darkened and quiet room.

After baseline blood samples were obtained, $\left[{ }^{2} \mathrm{H}_{5}\right]$ glycerol (MSD Isotopes, Montreal, Canada) dissolved in $0.9 \%$ sodium chloride and $\left[1-{ }^{13} \mathrm{C}\right]$ palmitic acid (MSD Isotopes) bound to human albumin (Cutter Laboratories, Emeryville, CA) $(2,24)$ were infused for $120 \mathrm{~min}$ by using a calibrated syringe pump (C. R. Bard Inc., North Reading, MA). The glycerol was administered by primed-constant infusion with a priming dose of $1.2 \mu \mathrm{mol} / \mathrm{kg}$ and an infusion rate of $\sim 0.08$ $\mu \mathrm{mol} \cdot \mathrm{kg}^{-1} \cdot \mathrm{min}^{-1}$, the palmitic acid was given by constant infusion at a rate of $\sim 0.04 \mu \mathrm{mol} \cdot \mathrm{kg}^{-1} \cdot \mathrm{min}^{-1}(25)$. The exact infusion rate was determined for each subject by measuring the concentration of isotope in the infusate. At $60 \mathrm{~min}$, propranolol, a nonselective $\beta$-adrenergic receptor antagonist, was infused $(0.05 \mathrm{mg} / \mathrm{kg}$ priming dose given over 4 min and $0.001 \mathrm{mg} \cdot \mathrm{kg}^{-1} \cdot \mathrm{min}^{-1}$ continuous infusion) for $1 \mathrm{~h}$ to evaluate the contribution of $\beta$-adrenergic stimulation. In previous studies we have found that the maximal antilipolytic effect during propranolol infusion occurs within $30 \mathrm{~min}$ (21).

Blood samples were withdrawn before starting the isotope infusion to determine baseline concentrations of hormones and substrates and background enrichment of glycerol and palmitic acid. Blood samples were taken at $45,50,55$, and 60 min to determine basal lipid kinetics and at $75,90,105,112$, and $120 \mathrm{~min}$ to measure the antilipolytic effect of propranolol infusion.

Analysis of samples. Blood for glycerol determination was collected in heparinized tubes and placed immediately in ice. The plasma was promptly separated by centrifugation and stored at $-20^{\circ} \mathrm{C}$ until analysis. $\left[2-{ }^{13} \mathrm{C}\right]$ glycerol was added as an internal standard to each sample, except the baseline sample. Plasma proteins were precipitated with barium hydroxide and zinc sulfate. After centrifugation the supernatant was passed through a mixed cation (Dowex AG-50W-X8) and anion (Dowex AGI-X8) exchange column. Trimethylsilyl derivatives of glycerol were formed and their isotopic enrichment was determined by gas chromatography mass spectrometry (GCMS) (26). Ions were selectively monitored at mass-to-charge ratio $(\mathrm{m} / \mathrm{e}) 205$, representing the unlabeled glycerol derivative, and at $\mathrm{m} / \mathrm{e} 208$ to quantify the isotopic enrichment in the plasma resulting from the $\left[{ }^{2} \mathrm{H}_{5}\right]$ glycerol infusion and at $\mathrm{m} / \mathrm{e} 206$ to quantify the enrichment resulting from the addition of $\left[2-{ }^{13} \mathrm{C}\right] \mathrm{glycerol}$. These values were used to calculate glycerol kinetics and glycerol concentration. The enrichment at $\mathrm{m} / \mathrm{e} 208$ was corrected for the contribution made by addition of the internal standard.

Blood for analysis of $\left[1-^{13} \mathrm{C}\right]$ palmitate enrichment was collected in the same manner as that for glycerol. Heptadecanoic acid was added to each sample as an internal standard. The fat-soluble fraction was extracted from the plasma, and the fatty acids were converted to their corresponding methyl esters as previously described $(27)$. $\left[1-{ }^{13} \mathrm{C}\right] \mathrm{pal}-$ mitic acid enrichment was determined by GCMS (model 5992, Hewlett-Packard Co., Palo Alto, CA). Palmitic acid concentration was quantified separately by gas chromatography.

Plasma glucose concentration was measured on a Glucose AutoAnalyzer (Beckman Instruments, Inc., Fullerton, CA) using a glucose oxidase reaction. Plasma insulin was determined by radio immunoassay (28) (Incstar Corporation, Stillwater, MN). Plasma epinephrine and norepinephrine concentrations were determined by radio-enzymatic assay using catechol- $O$-methyltransferase to label catecholamine-containing compounds with tritium-labeled $S$-adenosyl methionine (29). 
Calculations. The Ra of palmitic acid and glycerol in plasma were calculated by the equation described by Steele (30). During the basal period (45-60 $\mathrm{min}$ ) a physiological and isotopic steady state was present so that:

$R_{\mathrm{a}}=\frac{F}{I E}$

$R_{\mathrm{a}}$ is the rate of appearance of glycerol or palmitic acid in $\mu \mathrm{mol} \cdot \mathrm{kg}^{-1} \cdot \mathrm{min}^{-1}, F$ is the isotope infusion rate in $\mu \mathrm{mol} \cdot \mathrm{kg}^{-1} \cdot \mathrm{min}^{-1}$, and $I E$ is the isotopic enrichment at plateau. Because the infusion of stable isotopes contributed to the mass of the substrate pool, Eq. 1 was modified to:

$R_{\mathrm{a}}=\left(\frac{I E_{\mathrm{i}}}{I E_{\mathrm{p}}}-1\right) \times F$

$R_{\mathrm{a}}$ is the rate of appearance of glycerol or palmitic acid in $\mu \mathrm{mol} \cdot \mathrm{kg}^{-1} \cdot \mathrm{min}^{-1}, I E_{\mathrm{i}}$ is the isotopic enrichment of the infusate (mole percent excess), and $I E_{\mathrm{p}}$ is the isotopic enrichment of plasma (mole percent excess) at isotopic equilibrium.

The concentration of plasma glycerol was determined as follows:

Plasma glycerol $(\mu \mathrm{mol} / \mathrm{ml})=\frac{0.00198}{M P E}-0.00198$,

when $0.00198 \mu \mathrm{mol}$ of $\left[2{ }^{13} \mathrm{C}\right] \mathrm{glycerol}$ was added to each $1 \mathrm{ml}$ plasma sample, and MPE is the mole percent excess of each sample compared with a sample from the same subject without the addition of $\left[2-{ }^{13} \mathrm{C}\right]-$ glycerol.

The infusion of propranolol disturbed the steady-state conditions so that the Steele equation as it applies to the non-steady-state situation (30) was used. The effective volume of distribution used to calculate glycerol and palmitic acid $R_{\mathrm{a}}$ was $210 \mathrm{ml} / \mathrm{kg}$ and $40 \mathrm{ml} / \mathrm{kg}$, respectively. Spline fitting, a technique which smoothly joins polynomial function segments, was used in describing the enrichment and concentration data (31). The antilipolytic response to propranolol infusion was expressed both as the area between the basal (prepropranolol infusion) and propranolol infusion $R_{\mathrm{a}}$ values. Glycerol $R_{\mathrm{a}}$ is a better measure of the total rate of lipolysis than palmitic acid $R_{\mathrm{a}}$ because released glycerol cannot be directly reincorporated into triglyceride by adipose tissue (32).

The rate of TG-FA cycling represents the rate of reesterification of hydrolyzed triglycerides. It can be calculated as the difference between the rate of triglyceride oxidation, measured by indirect calorimetry, and the rate of triglyceride lipolysis, measured as glycerol $R_{\mathrm{a}}$. Therefore, whole-body triglyceride recycling was calculated as:

Total TG-FA cycling $(\mu \mathrm{mol})=R_{\mathrm{a}}$ glycerol $(\mu \mathrm{mol})$

- total triglyceride oxidation ( $\mu \mathrm{mol})$,

where palmityl-stearyl-oleyl-triglyceride $\left(\mathrm{C}_{55} \mathrm{H}_{104} \mathrm{O}_{6}, 7740 \mathrm{kcal} / \mathrm{mol}\right)$ was considered to be a typical triglyceride (33).

The energy cost of TG-FA cycling was estimated by calculating the number of "high-energy" phosphate bonds (ATP $\rightarrow$ ADP) required for reesterification. It was assumed that eight high-energy phosphate bonds were required per mole of triglyceride recycled (34). Because it is estimated that $18 \mathrm{kcal}$ of heat are released per mole of ATP hydrolyzed and synthesized (35), the total energy cost is $\sim 144 \mathrm{kcal} / \mathrm{mol}$ of triglyceride recycled.

Carbohydrate, fat, and protein oxidation rates and energy expenditure were calculated from measurements of oxygen consumption, carbon dioxide production, and estimated urinary nitrogen excretion (36).

Statistical analysis. One-way analysis of variance was used to test the significance of differences between the three groups.

\section{Results}

The characteristics of the study subjects are shown in Table I. All patients with cancer were recently diagnosed and had biopsy-proved squamous cell carcinoma of the esophagus. Dysphagia, decreased food intake, and weight loss were the major complaints that led all patients to medical evaluation. The cachectic patients free of cancer lost weight because of malabsorption (one patient with pancreatic insufficiency) or decreased food intake (two patients with dysphagia due to esophageal motility disorder or esophageal stricture, one patient with poor dentition, and one with depression). The five cachectic patients without cancer had lost $30,20,20,15$, and $10 \%$ of their body weight during the 6 mo before the study and were closely matched to the five patients with cancer who lost $28,20,18,15$, and $10 \%$ of their body weight. All cachectic patients were continuing to lose weight at the time of the study and none were weight-stable. The weight of the normal volunteers was stable before the study.

The basal plasma concentrations of glucose, insulin, and catecholamines are shown in Table II. The values in the patients with cancer did not differ from those in the cachectic controls or the normal-weight volunteers.

The $R_{\mathrm{a}}$ of glycerol and palmitic acid were greater in the patients with cancer than in the normal-weight volunteers (Table III) $(P<0.03)$. However, the lipolytic rates in the patients with esophageal cancer were the same as the values in the nutritionally matched cachectic patients without cancer.

The intravenous infusion of propranolol caused a prompt decrease in glycerol $R_{\mathrm{a}}$ (Table IV). The decrease in glycerol $R_{\mathrm{a}}$ during the 60 -min propranolol infusion, expressed as the absolute area between the glycerol $R_{\mathrm{a}}$ values during propranolol infusion and the basal (prepropranolol infusion) $R_{\mathrm{a}}$ value, was greater in both cachectic patient groups than in the normalweight volunteers, but the differences were not statistically significant $(P>0.05)$.

TG-FA cycling was measured in all cachectic patients and in 5 of 10 normal-weight volunteers (Table V). The rate of TG-FA cycling was numerically greater in both groups of cachectic patients than in the normal-weight volunteers, but the differences were not statistically significant $(P>0.05)$. The percentage of released fatty acids that was subsequently reesterified was the same in the normal-weight volunteers and the patients with esophageal cancer (60\%).

REE, measured by indirect calorimetry, was similar among groups (Table VI). REE was not significantly different from that predicted by the Harris-Benedict equation (37) in each of the three groups of study subjects.

Table II. Metabolic Factors in Healthy Normal-Weight Volunteers and Cachectic Patients with and without Cancer

\begin{tabular}{lccc}
\hline & $\begin{array}{c}\text { Normal-weight } \\
\text { volunteers }\end{array}$ & $\begin{array}{c}\text { Cachectic patients } \\
\text { without cancer }\end{array}$ & $\begin{array}{c}\text { Cachectic patients } \\
\text { with esophageal } \\
\text { cancer }\end{array}$ \\
\hline $\begin{array}{l}\text { Glucose }(m g / d l) \\
\text { Insulin }(\mu U / m l)\end{array}$ & $92 \pm 2$ & $98 \pm 3$ & $98 \pm 4$ \\
$\begin{array}{l}\text { Epinephrine } \\
(p g / m l)\end{array}$ & $5.5 \pm 0.7$ & $6.1 \pm 1.2$ & $7.3 \pm 1.3$ \\
$\begin{array}{l}\text { Norepinephrine } \\
(p g / m l)\end{array}$ & $62 \pm 12$ & $67 \pm 25$ & $60 \pm 14$ \\
\hline
\end{tabular}

Values are means \pm SE.

No statistically significant differences were found between any groups. 
Table III. Rate of Appearance $\left(R_{a}\right)$ of Glycerol and Palmitic Acid in Blood Plasma

\begin{tabular}{lcc}
\hline & Glycerol $R_{\mathrm{a}}$ & Palmitic acid $R_{\mathrm{a}}$ \\
\hline $\begin{array}{l}\text { Normal-weight volunteers } \\
\text { Cachectic patients } \\
\text { without cancer }\end{array}$ & $2.00 \pm 0.16^{*}$ & $1.13 \pm 0.11^{\ddagger}$ \\
$\begin{array}{l}\text { Cachectic patients with } \\
\text { esophageal cancer }\end{array}$ & $3.07 \pm 0.28$ & $1.60 \pm 0.20$ \\
\hline
\end{tabular}

Values are means $\pm \mathrm{SE}$ in micromoles per kilogram per minute.

* Value different from values for cachectic patients, $P=0.028$.

$¥$ Value different from values for cachectic patients, $P=0.015$.

\section{Discussion}

Four possible mechanisms could cause an increase in lipolytic rates in patients with cancer: $(a)$ increased lipolytic rates caused by decreased food intake and malnutrition; $(b)$ increased lipolysis when expressed per kilogram of body weight caused by body fat loss and an increased percentage of body weight as lean body mass; (c) stimulation of lipolysis caused by the stress response to illness with adrenal medullary stimulation, increased circulating catecholamines, and insulin resistance, and $(d)$ the release of lipolytic factors produced by the tumor itself or by myeloid tissue cells. The present study evaluated the importance of nutritional status, determined by percentage of body weight loss, on lipolytic rates comparing cachectic patients with cancer with both a cachectic cancer-free control group and healthy volunteers of normal weight. Each patient with cancer was matched with a patient who had lost a similar percentage of body weight during the same time period and had ingested the same meals the day before the study.

The results of the present study demonstrated that wholebody lipolytic rates were greater in the cachectic patients with squamous cell carcinoma of the esophagus than in the healthy volunteers. The younger age of our normal-weight volunteers does not affect this conclusion because lipolytic rates in the elderly are similar to those in young adult subjects when expressed per kilogram lean body mass or per kilogram body weight (25). That lipolytic rates did not differ in our patients with esophageal cancer compared with those in the nutritionally matched cachectic controls suggested that semistarvation or changes in body composition or both were responsible for the increase in lipolysis, rather than the presence of tumor

Table IV. Antilipolytic Effect of Propranolol Infusion

\begin{tabular}{|c|c|c|}
\hline & \multicolumn{2}{|c|}{$\begin{array}{l}\text { Decrease in glycerol } R_{\mathrm{a}} \text { during } 60 \text {-min } \\
\text { propranolol infusion }\end{array}$} \\
\hline & Mean \pm SE & Range \\
\hline & $\mu \mathrm{mol} / \mathrm{kg}$ per $h$ & $\mu \mathrm{mol} / \mathrm{kg} \mathrm{per} \mathrm{h}$ \\
\hline Normal-weight volunteers & $24 \pm 9$ & $5-51$ \\
\hline $\begin{array}{l}\text { Cachectic patients } \\
\text { without cancer }\end{array}$ & $46 \pm 12$ & $22-79$ \\
\hline $\begin{array}{l}\text { Cachectic patients with } \\
\text { esophageal cancer }\end{array}$ & $47 \pm 26$ & $1-147$ \\
\hline
\end{tabular}

Values are means $\pm \mathrm{SE}$.
Table V. Triglyceride Recycling Rate and Energy Cost

\begin{tabular}{lccc}
\hline & $\begin{array}{c}\text { Rate of } \\
\text { triglyceride } \\
\text { recycling }\end{array}$ & $\begin{array}{c}\text { Energy cost of } \\
\text { triglyceride recycling }\end{array}$ \\
\hline & $\mu \mathrm{mol} \cdot \mathrm{kg}^{-1} \cdot \mathrm{min}^{-1}$ & $\mathrm{kcal} / \mathrm{d}$ & $\% R E E$ \\
$\begin{array}{l}\text { Normal-weight volunteers } \\
\begin{array}{l}\text { Cachectic patients } \\
\text { without cancer }\end{array}\end{array}$ & $1.20 \pm 0.10$ & $19 \pm 2$ & $1.1 \pm 0.1$ \\
$\begin{array}{l}\text { Cachectic patients with } \\
\text { esophageal cancer }\end{array}$ & $2.18 \pm 0.37$ & $22 \pm 4$ & $1.8 \pm 0.3$ \\
\hline
\end{tabular}

Values are means $\pm \mathrm{SE}$.

itself. Many studies have demonstrated the sensitivity of adipose tissue to starvation and showed that glycerol and fattyacid turnover increased markedly in response to food deprivation $(21,24,25,31)$. It is likely that the cachectic patients had a higher percentage of body weight as lean body mass and a lower percentage of body weight as fat. Assuming that body composition in our subjects was the same as that reported in a similar group of normal volunteers $(21,31)$ and in sexmatched patients with gastrointestinal cancer who had the same percentage loss of body weight (38), theoretical lipolytic rates expressed per kilogram of fat mass and per kilogram lean body mass can be calculated. Lipid flux (glycerol $R_{\mathrm{a}}$ ) expressed per kilogram of fat mass, which represents the sensitivity of adipose tissue to lipolytic stimuli, was markedly increased in the cachectic patients $(21.7 \pm 4.4$ and $23.2 \pm 3.9 \mu \mathrm{mol} / \mathrm{kg}$ fat mass per min for tumor-bearing and non-tumor-bearing patients, respectively) when compared with that in normalweight volunteers $(10.5 \pm 0.8 \mu \mathrm{mol} / \mathrm{kg}$ fat mass per min) $(P$ $=0.002$ ). Lipid flux expressed per kilogram of lean body mass was still significantly higher in the cachectic patients $(3.5 \pm 0.6$ and $3.6 \pm 0.3 \mu \mathrm{mol} / \mathrm{kg}$ lean body mass per min, for tumorbearing and non-tumor-bearing patients, respectively) than in the normal-weight volunteers $(2.4 \pm 0.2 \mu \mathrm{mol} / \mathrm{kg}$ lean body mass per $\min )(P=0.03)$.

Five other studies have evaluated lipolytic rates in patients with cancer (10-14). Mean glycerol $R_{\mathrm{a}}$ ranged from $1.27 \pm 0.15$ (11) to $7.29 \pm 1.86(13) \mu \mathrm{mol} \cdot \mathrm{kg}^{-1} \cdot \mathrm{min}^{-1}$ in comparison with a value of $2.96 \pm 0.45 \mu \mathrm{mol} \cdot \mathrm{kg}^{-1} \cdot \mathrm{min}^{-1}$ in our study. Besides potential differences in food intake and body composition, the wide range of values may be related to differences in the severity of illness of the patients studied. Stimulation of lipolysis has

Table VI. Daily Predicted and Measured REE

\begin{tabular}{lccc}
\hline & $\begin{array}{c}\text { Predicted } \\
\text { REE }^{*}\end{array}$ & \multicolumn{2}{c}{ Measured REE } \\
\hline & $k c a l / k g$ & $k c a l / k g$ & $\%$ Predicted \\
$\begin{array}{l}\text { Normal-weight volunteers } \\
\text { Cachectic patients } \\
\text { without cancer }\end{array}$ & $24.0 \pm 0.7$ & $22.4 \pm 0.6$ & $94 \pm 3$ \\
$\begin{array}{l}\text { Cachectic patients with } \\
\text { esophageal cancer }\end{array}$ & $25.2 \pm 1.4$ & $26.3 \pm 0.9$ & $105 \pm 4$ \\
\hline
\end{tabular}

Values are means $\pm \mathrm{SE}$.

* Based on Harris-Benedict equation. 
been well documented as part of the metabolic response to stressful illness (12) or injury (19). Our patients had a low level of metabolic stress as indicated by their normal concentrations of plasma catecholamines and normal energy expenditure. This does not mean, however, that our patients did not have significant disease. Indeed, although one patient was still alive 15 mo later, four of our five patients with cancer died within $12 \mathrm{mo}$ (mean $\pm \mathrm{SE}, 7 \pm 2 \mathrm{mo}$ ) of the study. The level of stress in the patients reported in other studies is difficult to evaluate but may have been greater than the level in our patients. Energy expenditure (14), plasma cortisol (12), or urinary vanillylmandelic acid (13) was reported to be increased in some studies. Although the precise mechanisms are not known, a larger tumor load, other tumor types, active inflammation, or cancer therapy could have increased the level of stress in these patients. Differences in tumor stage or tumor types among studies may have influenced lipolytic rates if they caused the release of endogenous lipolytic factors. In contrast with previous studies, we studied a uniform group of patients with one type and stage of tumor. The relationship between possible lipolytic factors such as tumor necrosis factor, a myeloid cell-derived polypeptide possibly associated with cancer (39), and esophageal cancer is not known. Although tumor necrosis factor was not measured in our study, it was probably not an important factor in stimulating lipolysis because of the lack of fever or increased oxygen consumption, which has been associated with its administration when given at lipolytic doses (40). Other, as yet unknown, mediators cannot be excluded. Finally, it is possible that the analytical difficulties of the enzymatic technique used in measuring glycerol concentration in the earlier studies contributed to the variability in the reported data.

The mean decrease in lipolytic rates during $\beta$-adrenergic receptor blockade with propranolol infusion was twofold greater in both groups of cachectic patients than in the normal-weight subjects. Although this observation suggests that $\beta$-adrenergic stimulation contributed to the increase in lipolysis in the cachectic patients, the differences between groups were not statistically different, because of the variability in the response to propranolol in the patients with cancer.

TG-FA cycling tended to be greater in the cachectic patients than in the volunteers of normal weight because of the increase in triglyceride mobilization (fatty acid release) without a concomitant increase in energy expenditure (fatty acid oxidation), but the differences were not statistically significant. It has been demonstrated both theoretically (35) and empirically (41) that TG-FA cycling can enhance the regulation of metabolic pathways. The "excess" mobilization of fat and subsequent reesterification to triglycerides may have increased the sensitivity and flexibility of fuel regulation in the cachectic patients whose energy intake was inadequate. The calculated energy cost of the increased TG-FA cycling in the cachectic patients was minimal. Total TG-FA cycling accounted for $<2 \%$ of REE in both the normal volunteers and cachectic subjects. REE in the patients with esophageal cancer was similar to the expenditure in the normal and cachectic controls and to the predicted REE. These results are in agreement with a recent study which found that REE in malnourished patients with esophageal cancer was the same as that in normal controls (42).

In conclusion, this study has demonstrated that the increase in whole-body lipolysis and TG-FA cycling in cachectic patients with squamous cell carcinoma of the esophagus are appropriate for their nutritional state and are not necessarily caused by tumor-induced abnormalities in lipid metabolism. These results should not be extrapolated to patients with other tumor types or to patients with the same tumor but in a different clinical setting. Our patients were carefully selected to avoid factors that might influence lipid metabolism, such as "inflammatory stress," liver metastases, and previous cancer therapy. More studies in patients with individual tumor types and using appropriate nutritionally matched controls are needed to investigate possible metabolic abnormalities in patients with cancer to distinguish the effect of the tumor alone from confounding influences.

\section{Acknowledgments}

The authors thank Dr. J. B. Zwischenberger for patient referrals, Dr. M. Shike for his support of this project, LeAnne Romano, Susan Fons, and Alice Cullu for their technical assistance, and Billie Roach for preparation of the manuscript.

This study was supported by National Cancer Institute Grant CA50330, National Institutes of Health Grant DK38010, General Clinical Research Center Grant RR-00073, and grants from The Shriners Hospitals, the International Life Sciences Institute-Nutrition Foundation, and The American Institute for Cancer Research. S. Klein is supported by an American Gastroenterological Association/ Merck Sharp \& Dohme Research Award.

\section{References}

1. Shike, M., D. M. Russell, A. S. Detsky, J. E. Harrison, K. G. McNeill, F. A. Shepherd, L. Feld, W. K. Evans, and K. N. Jeejeebhoy. 1984. Changes in body composition in patients with small-cell lung cancer. Ann. Intern. Med. 101:303-309.

2. Cohn, S. H., W. Gartenhaus, D. Vartsky, A. Sawitsky, I. Zanzi, A. Vaswani, S. Yasumura, K. Rai, E. Cortes, and K. J. Ellis. 1981. Body composition and dietary intake in neoplastic disease. Am. J. Clin. Nutr. 34:1997-2004.

3. DeWys, W. D., C. Begg, P. T. Lavin, P. R. Band, J. M. Bennett, J. R. Bertino, M. H. Cohen, H. O. Douglas, P. F. Engstrom, E. Z. Ezdinli, J. Horton, G. J. Johnson, C. G. Moerkl, M. M. Oken, C. Perlig, C. Rosenbaum, M. N. Silverstein, R. T. Skeel, R. W. Sponzo, and D. C. Tormey. 1980. Prognostic effect of weight loss prior to chemotherapy in cancer patients. Am. J. Med. 69:491-497.

4. Stanley, K. E. 1980. Prognostic factors for survival in patients with inoperable lung cancer. J. Natl. Cancer Inst. 65:25-32.

5. Leiter, L. A., and E. B. Marliss. 1982. Survival during fasting may depend on fat as well as protein stores. JAMA (J. Am. Med. Assoc.) 248:2306-2307.

6. Costa, G., and J. F. Holland. 1962. Effect of Krebs-2 carcinoma on the lipid metabolism of male Swiss mice. Cancer Res. 22:10811083.

7. Mider, G. B., C. D. Sherman, Jr., and J. J. Morton. 1949. The effect of Walker carcinoma 256 on the total lipid content of rats. Cancer Res. 9:222-229.

8. Thompson, M. P., J. E. Koons, E. T. H. Tan, and M. R. Grigor. 1981. Modified lipoprotein lipase activities: rates of lipogenesis and lipolysis as factors leading to lipid depletion in C57BL mice bearing the preputial gland tumor, ESR-586. Cancer Res. 41:3228-3232.

9. Kralovic, R. C., E. A. Zepp, and R. J. Cenedella. 1977. Studies of the mechanism of carcass fat depletion in experimental cancer. Eur. $J$. Cancer. 13:1071-1079.

10. Jeevanandam, M., G. D. Horowitz, S. F. Lowry, and M. F. Brennan. 1986. Cancer cachexia and the rate of whole body lipolysis in man. Metabolism. 35:304-310.

11. Tibbling, G. 1970. Glycerol and free fatty acid turnover in leukaemia and hyperthyroidism. Scand. J. Clin. Lab. Invest. 26:179184. 
12. Shaw, J. H. F., and R. R. Wolfe. 1987. Fatty acid and glycerol kinetics in septic patients and in patients with gastrointestinal cancer. Ann. Surg. 205:368-376.

13. Eden, E., S. Edstrom, K. Bennegard, L. Lindmark, and K. Lundholm. 1985. Glycerol dynamics in weight-losing cancer patients. Surgery (St. Louis). 97:176-184.

14. Legaspi, A., M. Jeevanandam, H. F. Starnes, and M. F. Brennan. 1987. Whole body lipid and energy metabolism in the cancer patient. Metabolism. 36:958-963.

15. Waterhouse, C., and J. H. Kemperman. 1971. Carbohydrate metabolism in subjects with cancer. Cancer Res. 31:1273-1278.

16. Lindmark, L., K. Bennegard, E. Eden, L. Eckman, T. Schersten, G. Svaninger, and K. Lundholm. 1984. Resting energy expenditure in malnourished patients with and without cancer. Gastroenterology. 87:406-408.

17. Dempsey, D. T., I. D. Feurer, L. S. Knox, L. O. Crosby, G. P. Buzby, and J. L. Mullen. 1984. Energy expenditure in malnourished gastrointestinal cancer patients. Cancer (Phila.). 53:1265-1273.

18. Peacock, J. L., R. I. Inculet, R. Corsey, D. B. Ford, W. F. Rumble, D. Lawson, and J. A. Norton. 1987. Resting energy expenditure and body cell mass alterations in noncachectic patients with sarcomas. Surgery (St. Louis). 102:465-473.

19. Wolfe, R. R., D. N. Herndon, F. Jahoor, H. Miyoshi, and M. Wolfe. 1987. Effect of severe burn injury on substrate cycling by glucose and fatty acids. N. Engl. J. Med. 317:403-408.

20. Miyoshi, H., G. I. Shulman, E. J. Peters, M. H. Wolfe, D. Elahi, and R. R. Wolfe. 1988. Hormonal control of substrate cycling in humans. J. Clin. Invest. 81:1545-1555.

21. Klein, S., E. J. Peters, O. B. Holland, and R. R. Wolfe. 1989. Effect of short- and long-term $\beta$-adrenergic blockade on lipolysis fasting in humans. Am. J. Physiol. 257:E65-E73.

22. Russell, D. M., M. Shike, E. B. Marliss, A. S. Detsky, F. A. Shepherd, R. Feld, W. K. Evans, and K. N. Jeejeebhoy. 1984. Effects of total parenteral nutrition and chemotherapy on the metabolic derangements in small cell lung cancer. Cancer Res. 44:1706-1711.

23. McGuire, E. A. H., J. H. Helderman, J. D. Tobin, R. Andres, and M. Berman. 1976. Effects of arterial versus venous sampling on analysis of glucose kinetics in man. J. Appl. Physiol. 41:565-573.

24. Klein, S., O. B. Holland, and R. R. Wolfe. 1990. Importance of blood glucose concentration in regulating lipolysis during fasting in humans. Am. J. Physiol. 258:E32-E39.

25. Klein, S., V. R. Young, G. L. Blackburn, B. R. Bistrian, and R. R. Wolfe. 1986. Palmitate and glycerol kinetics during brief starvation in normal weight young adult and elderly subjects. J. Clin. Invest. 78:928-933.

26. Wolfe, R. R. 1985. Tracers in Metabolic Research: Radioisotope and Stable Isotope/Mass Spectrometry Methods. Alan R. Liss, Inc., New York. 261-263.

27. Wolfe, R. R., J. E. Evans, C. J. Mullany, and J. F. Burke. 1980
Measurement of plasma free fatty acid turnover and oxidation using [1-13 C]palmitic acid. Biomed. Mass Spectrom. 7:168-171.

28. Hales, C. N., and P. J. Randle. 1963. Immunoassay of insulin with insulin antibody precipitate. Biochem. J. 88:137-146.

29. Hussain, M. N., and C. R. Benedict. 1985. Radioenzymatic microassay for simultaneous estimations of dopamine, norepinephrine, and epinephrine in plasma, urine, and tissues. Clin. Chem. 31:1861-1864.

30. Steele, R. 1959. Influences of glucose loading and of injected insulin on hepatic glucose output. Ann. NY Acad. Sci. 82:420-430.

31. Wolfe, R. R., E. J. Peters, S. Klein, O. B. Holland, J. I. Rosenblatt, and H. Gary. 1987. Effect of short-term fasting on lipolytic responsiveness in normal and obese human subjects. Am. J. Physiol. 252:E189-E196.

32. Lin, E. C. C. 1977. Glycerol utilization and its regulation in mammals. Annu. Rev. Biochem. 46:765-795.

33. Hirsch, J. 1965. Fatty acid patterns in human adipose tissue. In Handbook of Physiology. Adipose Tissue. American Physiology Society, Washington, DC. 181-189.

34. Elia, M., C. Zed, G. Neale, and G. Livesey. 1987. The energy cost of TG-FA recycling in nonobese subjects after an overnight fast and four days of starvation. Metabolism. 36:252-255.

35. Newsholme, E. A., and B. Crabtree. 1976. Substrate cycles in metabolic regulation and in heat generation. Biochem. Soc. Symp. 41:61-109.

36. Frayn, K. N. 1983. Calculation of substrate oxidation rates in vivo from gaseous exchange. J. Appl. Physiol. 55:628-634.

37. Harris, J. A., and F. G. Benedict. 1919. A Biometric Study of Basal Metabolism in Man. Carnegie Institution of Washington, DC. Publication No. 279.

38. Cohn, S. H., W. Gartenhaus, A. Sawitsky, K. Rai, I. Zanzi, A. Vaswani, K. J. Ellis, S. Yasumura, E. Cortes, and D. Vartsky. 1981. Compartmental body composition of cancer patients by measurement of total body nitrogen, potassium, and water. Metabolism. 30:222229.

39. Balkwill, F., R. Osborne, F. Burke, S. Naylor, D. Talbot, H. Durbin, J. Tavenier, and W. Fiers. 1987. Evidence for tumor necrosis factors/cachectin production in cancer. Lancet. ii:1229-1232.

40. Starnes, H. F., R. S. Warren, M. Jeevanandam, J. L. Gubrilove, W. Larchian, H. F. Oettgen, and M. F. Brennan. 1988. Tumor necrosis factor and the acute metabolic response to tissue injury in man. J. Clin. Invest. 82:1321-1325.

41. Wolfe, R. R., S. Klein, F. Carraro, and J.-M. Weber. 1981. Role of triglyceride-fatty acid cycle in controlling fat metabolism in humans during and after exercise. Am. J. Physiol. 258:E382-E389.

42. Thomson, S. R., A. Hirshberg, A. A. Haffejee, and W. K. J. Huizinga. 1990. Resting metabolic rate of esophageal carcinoma patients: a model for energy expenditure in a homogenous cancer population. J. Parenter. Enteral Nutr. 14:119-121. 